\title{
Adolescent Mental Health Research in Macau
}

\author{
Pou-Chan Lo', Sau-Kam Chan' ${ }^{2}$ \\ ${ }^{1}$ Service Supervisor, Baptist Oi Kwan Social Service of Macau, Macau, China \\ ${ }^{2}$ Senior Service Coordinator, Baptist Oi Kwan Social Service of Hong Kong, Hong Kong, China \\ Email: ic.mt@bokss.net
}

Received September 2014

\begin{abstract}
Adolescence is an important period in which an individual experiences significant changes in physical, mental and social aspects. When an adolescent with risk of having depression or anxiety disorder cannot derive appropriate treatment in an earlier stage, they may encounter a higher tendency to trigger onset of the problems in their adulthood. So the adolescent mental health is too important to neglect However, here in Macau, there is still no research investigating the issue of adolescent daily emotional problem. Therefore, this research will look into adolescent mental health in Macau, emotional problems and the relationship between thinking strategy and difficultyhandling strategy. This research uses DASS21 questionnaire, Cognitive Emotion Regulation Questionnaire (CERQ), and Pressure Manage Mode as investigation tools. 2780 pieces of questionnaires were sent out and 2766 questionnaires were successfully responded. The respondent rate is up to $\mathbf{9 9 . 5 \%}$. The research found that about $\mathbf{2 2 \%}$ adolescent have serious anxiety symptoms. The more negative thinking strategies they adopted to face the challenges or dissatisfaction, the higher level of depression, anxiety and stress they suffered. Furthermore, the adolescent tend to avoid and neglect the problems when they undergo emotional problems.
\end{abstract}

\section{Keywords}

Depressive Symptom, Anxiety Symptom, Stress Symptom, Difficulty-Handling Strategy, Cognitive Emotion Regulation Strategy

\section{Background and Literature Review}

Adolescence is the developmental stage between children and adult, where it is a very important transitional period of everyone. Adults give adolescent more freedom than children in order to help them mold themselves, learn to face problem, and take responsibilities. Once after entering secondary school, many new challenges are awaiting them. In the new environment, they enlarge their social circle, meet new friends, attend new classes and adopt a new learning method. So in this situation, they cannot always avoid failure. If they do not use the right way to face and overcome difficulties, they will feel excessively stressed easily and they may be more fragile to depressive and anxious emotions.

Researches in Hong Kong showed that, from high grades to college students, they all suffered from depres- 
sive and anxiety emotion. For example, one research found that, about $21 \%$ of 300 participants who are students from grade four to grade six suffered from depressive emotion [1]; another research focusing on middle school students showed that about $28 \%$ of 2000 students suffered from depressive emotion [2]. Another research focusing on college students in the Mainland and Hong Kong found that about $17 \%$ college students in Hong Kong suffered from depressive emotion, and the rate was twice of that in Beijing. Concerning adolescent anxiety, some researches showed that more adolescents in Hong Kong suffered all kinds of anxiety disorder than in Germany, such as generalized anxiety disorder, panic disorder, separation anxiety disorder, social anxiety disorder and obsessive-compulsive disorder (OCD), and etc [3]. These researches were not yet carried out in Macau; however, Macau and Hong Kong are sharing a similar background in some extent. For example, both of them have ever been the western country's colonies; their education systems have ever been influenced by the West. Both of them are cities where the West meets the East; both of them are service-oriented society, and etc. All these may reflect that the adolescent in Macau and Hong Kong are both influenced by similar social and environmental factors. However, there is no research focusing on the adolescent emotional health in Macau until now. Therefore, the first goal of this research is to understand the situation of adolescent emotional health in Macau.

If the adolescent depressive and anxiety emotion cannot be treated appropriately, the situation can be exacerbated seriously. Researches found that the adolescent influenced by depression and anxiety achieved lower level of social skill, self-esteem, and academic performance [4] [5]. They were also easier to have problematic behaviors, criminal behaviors [6] [7], and mental health problems [8]. These may be related to the idea that how to value children's behavior in Chinese society. Adults, such as teachers and parents, usually positively treat children's flinch, diffidence and quiet as steady, mature, and tolerant behavior [9], while neglect children's depression and anxiety, so these situation were not recognized and treated. Hence another goal of this research is to increase parents and teachers' awareness about adolescent emotion health.

Since adolescent depression and anxiety influence their growing and mental health seriously, it is needed to find out the elements that trigger the problems. The Western and Hong Kong's literature showed that daily trivial problems, such as conflict and friction among friends, family members, and teachers, difficulties in study, bullying from the internet, and domestic problems, are all source of adolescent stress [10] [11]. However, when they have troubles, not every adolescent could feel the stress, or even experience the depressive and anxious emotions. One key element is how they deal with these daily and inevitable problems.

Handling difficulty refers to the way how ones encounter the problem when they cannot solve the current issue with their abilities and resource at the moment. It includes two aspects: cognition (view of things) and behavior (treatment) [12]. Garnefski, Kraaij, and Spinhoven [13] pointed out that thinking and behavior are two different processes to handle difficulty. If idea or thinking does not change, the behavior will be difficult to change. If we try to help the adolescent to learn how to handle difficulty, so as to improve their emotion health, we should also study their cognition and behavior modes.

Garenfski et al. [13] put forward nine cognitive emotion regulation strategies. Those are views when people encounter difficulties, and these views will influence people's responses to emotion. These emotion regulation strategies can be divided into two kinds, positive ones and negative ones. The negative strategies include: 1) Self-blaming: Thoughts of blaming yourself for what you have experienced; 2) Rumination: Thinking about the thoughts and feelings associated with the negative event; 3) Catastrophising: Thoughts of explicitly emphasizing the terror of an experience, and the belief that the terror is worse than ever; 4) Other-blame: Thoughts of putting the blame for what you have experienced on others. The five kinds of positive strategies include: 1) Acceptance: Thoughts of accepting what you have experienced and resigning yourself to what has happened; 2) Positive refocusing: Thinking about joyful and pleasant issues instead of thinking about the actual event; 3) Refocusing on planning: Thinking about what steps to take and how to handle the negative event; 4) Positive Reappraisal: Thoughts of attaching a positive meaning to the event in terms of personal growth; 5) Putting into perspective: Thoughts of playing down the seriousness of the event or emphasizing its relativity when compared to other events.

Garenfski and his group did a lot of research on how the cognitive emotion regulation influences mental health, and proved that when adolescence and adults encounter difficulty, the more negative strategy they prefer to use, the more serious depressive symptom and anxiety symptom they have, and vice versa [13]-[15]. For example, Martin and Dahlen [16] reported that the using of self-blaming, rumination, and catastrophising can predict depressive symptom and anxiety symptom. And the psychopaths use more these three negative strategies 
than the ordinary.

The above mentioned difficulty-handling behaviors also influence mental health. The difficulty-handling strategies that usually used by adolescents include: solving problem directly, looking for emotion support, release behaviors (such as shouting aloud, saying dirty words, destroy subjects, etc.), and escape, etc. Theoretically, release behaviors and escape can aggravate the negative emotion carried by unpleasantness. The former one just relieves negative emotion temporarily, but may arouses more problems and interpersonal conflicts; the later one just boosts mood temporarily, while it cannot solve the real problem, or even make it worse. Some researches pointed out that the adolescents with release behaviors have more emotional problems than those seeking for emotion support [17]. Murberg and Bru [18] also reported that those adolescents who use more aggressive strategies, such as shouting aloud, saying dirty words, and destroying subjects, suffer more serious depressive emotion. And there is a positive correlation between escape behaviors and adolescent depressive emotion.

On the contrary, some literature pointed out that dealing with problems directly and looking for emotion support can relieve negative emotion. Both of these two strategies have a kind of positive and active attitude. The former one is trying different kinds of ways to solve problems, while the later one includes seeking for emotion support from the people around actively. Research found that the children and the adolescent seeking help from parents or others have less depressive emotion.

Based on the above literatures and research, this research will discuss the relationship among adolescent emotion problems, daily problems, thinking strategies and difficulty-handling strategies.

\section{Methodology}

\subsection{Data Collection}

The questionnaires were distributed from Oct, 2013 to Jan, 2014, and they were all conducted in self-report measure.

\subsection{Basic Information about Participant}

This research invited 2766 participants who study in eight middle schools in Macau. They were 1124 male students (40.64\%), 1630 female students (58.93\%), and 12 students who did not fill in the blank Gender (0.43\%). There were 543 students of grade one (19.6\%), 751 students of grade two (27.2\%), 732 students of grade three (26.5\%), 378 students of grade four (13.7\%), 187 students of grade five (6.8\%), and 175 students of grade six (28.33\%). For the age of participants, 21 of them were under 11 years old $(0.76 \%), 1949$ of them were between 12 - 15 years old (70.54\%), 783 of them were between 16 - 19 years old (28.33\%), and 10 of them were over 20 years old $(0.36 \%)$.

\section{Measuring Tool}

\subsection{The Situation of Adolescent Emotion}

Using Depression Anxiety and Stress Scale [19] [20] as tool to investigate adolescent three negative emotions: depression, anxiety and stress. Depressive symptoms include irritability, desperation, feeling that life is worthless, feeling that oneself is worthless, not interested in people or things around, and a kind of feeling that cannot be happy. Anxiety symptoms include natural physiological reactions, for example: hand tremor, difficult breathing, muscle reaction, feeling abnormal heart rhythms without doing obvious physical work, subjective feeling of worrying for some situations. While stress symptoms include people have long-term feeling of nervousness, stress, and overreacting; pressure and tightness, being easily angered without any special reason. The questionnaire has 21 questions. The adolescent reported the appearing rate of their three kinds of emotions in last week by 0 - 3 points. In this research, the reliability (Cronbach alpha) of these emotion are, depression: 0.84 ; anxiety: 0.80 ; and tension: 0.83 .

\subsection{Adolescent Daily Troubles/Problems}

In order to understand the source of adolescent pressure, this part lists nine kinds of daily problems that adolescent usually have, such as dealing with peer, dealing with family members, study, dealing with teachers, the future, appearance and figure, problems related to the opposite sex, family problems, and interpersonal relationship in Internet, etc. The adolescent reported the appearing rate of these problems by 0 - 3 points. In this re- 
search, the adolescent daily trouble is the sum of these nine items.

\subsection{The Adolescent Cognitive/Thinking Mode When They Encounter Difficulties}

This part uses Cognitive Emotion Regulation Questionnaire designed by Garenfski, et al. [13] as measurement instrument. The questionnaire has 36 questions, and was divided into nine parts. The adolescent reported the rate of using nine kinds of cognitive emotion regulation strategies by 0 - 3 points. In this research, the reliability of nine parts is ideal, the lowest one is 0.66 , and the highest one is 0.81 .

\subsection{The Adolescent Behavior of Handling Difficulty}

This part has 7 questions altogether. It investigates the rate of using five kinds of difficulty-handling behavior when adolescent encounter difficulties. These behaviors include solving problem directly (turn to people around or internet for help), looking for emotion support (from people around or internet), looking for professional's help, release behaviors and escape. The adolescent answer questions by 1 - 5 points.

\section{Result and Discussion}

\subsection{The Adolescent Emotion Situation}

Table 1 listed average value and standard deviation of the male students and the female students, two groups of different age. For the average value, in Macau, Middle school students' depressive symptom was between the normal level and mildly depression ( 0 - 4 is normal, 4 - 5 is mildly depression). The average of anxiety symptom was in the mildly anxiety level (4 - 6 is mildly anxiety), while stress was in normal level ( 0 - 7 is normal). This result was similar Hong Kong's research. Wong, Cheung, Chan, Ma, and Tang [21] used the same instrument (DASS 21) to investigate 7915 college students in Hong Kong. The average scores were: depressive symptom: 4.33; anxiety symptom: 4.68; stress symptom: 6.99. But another research showed that the average of depressive symptom of college students in Hong Kong was 5.16 [22].

Generally speaking, both of the Western and Hong Kong research reported that the female students got higher score than the male student (e.g., [23]-[26]). From Table 2, we can see that there was no distinguished difference of average values of depressive symptom between the male students and female students. This point was different from the result of the Western and Hong Kong's research. But the situation of anxiety and stress, this research got the same result with the Western research, where the female students got higher score than the male students'. For age difference, the students in high grade got higher score of anxiety and stress than the students in lower grade, it showed that they were more anxious and bore more stress than the students in lower grade.

Table 2 listed the students' percentage who were influenced by different degrees of negative emotion. Data showed that about $11 \%$ students had serious to very serious depressive symptom, and the percentage of students influenced by serious to very serious stress was similar. It should be noted that about $22 \%$ of students influenced by serious to very serious anxiety. But the rate was lower than the result of the research in Hong Kong. The research showed that about $30 \%$ of 2899 students had serious anxiety emotion [2].

\subsection{Adolescent Daily Problems: The Origin of Stress}

The data of Table 3 showed that the most serious trouble for middle school students in Macau was study, about one third students always had problem in study. The second problem was the future (20.7\%). In other words, the

Table 1. Average value, standard deviation, difference of age, difference of gender.

\begin{tabular}{ccccccc}
\hline & Male & Female & T & 11 to 14 Years Old & 15 to 19 Years Old & $t$ \\
\hline depression & $4.82(4.58)$ & $4.76(4.51)$ & 0.37 & $4.65(4.59)$ & $4.94(4.49)$ & 0.20 \\
anxiety & $4.49(4.13)$ & $4.87(3.97)$ & $-2.4^{*}$ & $4.53(3.90)$ & $4.88(4.16)$ & $3.22^{*}$ \\
stress & $6.04(4.62)$ & $6.66(4.59)$ & $-3.46^{* *}$ & $6.13(4.68)$ & $6.71(4.55)$ & $4.12^{* *}$ \\
\hline
\end{tabular}

${ }^{*} p<0.05 ; p<0.01$. 
Table 2. Number and percentage of students with different degree of three kinds of negative emotion.

\begin{tabular}{cccc}
\hline & All Students & Male & Female \\
\hline Depression & $N=2748$ & $n=1113$ & $n=1623$ \\
\hline No depressive symptom & $1597(58.1 \%)$ & $641(57.6 \%)$ & $948(58.4 \%)$ \\
Mildly to middle degree of depressive symptom & $813(29.6 \%)$ & $322(28.9 \%)$ & $489(30.1 \%)$ \\
Serious to very serious depressive symptom & $338(12.3 \%)$ & $150(13.5 \%)$ & $186(11.5 \%)$ \\
No answer & 18 & 11 & $7=1625$ \\
Anxiety & $N=2752$ & $n=1115$ & $741(45.6 \%)$ \\
No anxiety symptom & $1316(47.8 \%)$ & $367(50.9 \%)$ & $523(32.2 \%)$ \\
Mildly to middle degree of anxiety symptom & $839(30.5 \%)$ & $234(21.0 \%)$ & $361(22.2 \%)$ \\
Serious to very serious anxiety symptom & $597(21.7 \%)$ & 9 & 5 \\
No answer & 14 & $n=1113$ & 1625 \\
Stress & $N=2750$ & $726(65.2 \%)$ & $992(61 \%)$ \\
No stress symptom & $1727(62.8 \%)$ & $273(24.5 \%)$ & $427(26.3)$
\end{tabular}

Table 3. The appearance rate of daily problems that adolescent always encounter.

\begin{tabular}{|c|c|c|c|c|}
\hline \multirow[t]{2}{*}{ Daily problem } & \multicolumn{4}{|c|}{ Percentage } \\
\hline & No & Rarely & Sometimes & Frequently \\
\hline Dealing with peer & $32.2 \%$ & $47.2 \%$ & $16.4 \%$ & $4.2 \%$ \\
\hline Dealing with family members & $27.1 \%$ & $39.1 \%$ & $24.6 \%$ & $9.2 \%$ \\
\hline Study & $7.7 \%$ & $19.2 \%$ & $38.6 \%$ & $34.6 \%$ \\
\hline Dealing with teachers & $34.9 \%$ & $42 \%$ & $17.4 \%$ & $5.7 \%$ \\
\hline The future & $19.6 \%$ & $26.3 \%$ & $33.4 \%$ & $20.7 \%$ \\
\hline Appearance and figure are not ideal & $23.3 \%$ & $30.8 \%$ & $28.1 \%$ & $17.8 \%$ \\
\hline Problems related with the opposite sex & $56.4 \%$ & $25.5 \%$ & $11.6 \%$ & $6.5 \%$ \\
\hline Family problems & $66.7 \%$ & $20.1 \%$ & $9.3 \%$ & $3.8 \%$ \\
\hline Interpersonal relationship in internet & $80.7 \%$ & $14.2 \%$ & $3.2 \%$ & $1.8 \%$ \\
\hline
\end{tabular}

factors that had more influence on middle school students' emotion in Macau were all related to study, because the scholastic achievement can influence the future directly. Besides, it may also be related to Chinese values. In Chinese society, education is always recognized as tool to move upward, and Chinese parents always treat scholastic achievement as one important parenting goal. A research compared middle school students in Hong Kong and Germany found that the students in Hong Kong had stronger motivation in "study is better than other" and "get reward for scholastic achievement", and also had more serious anxiety. But these two motivations were not the factors that aroused German students' anxiety [3]. Another research in Hong Kong found that about 80\% of adolescents, who were influenced by generalized anxiety disorder, admitted that academic performance would be one of the main sources of anxiety [27]. From the result of above research, it revealed that academic performance was ranked so important in the Chinese society. 
The third trouble of middle school students in Macau was their appearance and figure were not ideal (17.8\%). This may reflect that they were influenced by media, advertisement, and idols, etc., and weighed heavier on their appearance much more than before. Teachers and social workers should pay attention to this point, because the appearance had hereditary element. Students might develop low self-respect when they cannot accept their appearance or they overly focus on one's outlook. So adults should help the adolescent understand that characters and values are more important than appearance.

Gender difference only appeared in one daily problem. Male students got higher score than female students' in the item "problems related with the opposite sex: For example, cannot get a boyfriend/girlfriend; have conflict with boyfriend/girlfriend". Grade difference listed in Table 4, it showed that there was no grade difference in peers (interpersonal issues with peer or in internet).

\subsection{Adolescent Difficulty-Handling Behavior}

Table 4 showed the rate of adolescent difficult-handling behavior when they encountered difficulties. The data showed that when students were trapped in emotional troubles, most of them "find a way to release, such as shouting aloud, drinking alcohol, smoking, eating a lot, shopping, playing video games, etc.” (23.6\%), "talk with others about my problem in order to solve it" (23.4\%), "talk and share with others to relax my anxiety" (22.4\%), and they seldom "turn to professional for help".

We should pay attention to several points in the result. First, when middle school students in Macau encountered difficulties, about half of them never or seldom talk their problems with others, such as family members and friends, to release their anxiety or to solve the problem.

For the gender difference, female students got higher score than male students' in two items, "talk with family members, friends about my problem to release anxiety" and "talk with family members, friends about my problem to solve it". While male students got higher score than female students in these items, "find a way to release, such as shouting aloud, drinking alcohol, smoking, eating a lot, shopping, playing video games, etc.", "Turn to professional for help", and "look for information in internet to solve problem".

\subsection{The Relationship among Negative Emotion and Adolescent Daily Problem, Difficulty-Handling Behavior and Cognitive Emotion Regulation Strategy}

This part used regression analysis. Since students of grade one and two used less cognitive emotion regulation strategy than students of other grades, all the students were divided into two groups: the junior group (grade one and grade two) and the senior group (grade three to grade six). The result was listed in Table 5.

Generally speaking, for junior or senior middle school students, all of the daily problems/troubles were important source of depression, anxiety and stress. In other words, their difficulty-handling behavior and thinking about negative things were important factors to influence emotion. They can release or intensify the negative emotion.

In different difficulty-handling behaviors, the item that had the most significant influence was "to neglect problem". No matter junior students or senior students, the more frequent they used this strategy, the more se-

Table 4. The rate of adolescent difficult-handling behavior when they encounter difficulties.

\begin{tabular}{|c|c|c|c|c|c|}
\hline Difficulty-handling behavior & Never & Sometimes & Fifty-fifty chance & Frequently & Usually \\
\hline Talk with family members, friends about my problem to relax anxiety & $18.6 \%$ & $31.2 \%$ & $26.8 \%$ & $15 \%$ & $8.4 \%$ \\
\hline Talk with family members, friends about my problem to solve it & $18.4 \%$ & $31.1 \%$ & $28.1 \%$ & $15.5 \%$ & $6.9 \%$ \\
\hline $\begin{array}{l}\text { Find a way to release, such as shouting aloud, drinking alcohol, } \\
\text { smoking, eating a lot, shopping, playing video games, etc. }\end{array}$ & $35.4 \%$ & $23.1 \%$ & $18 \%$ & $13.3 \%$ & $10.3 \%$ \\
\hline Neglect the problem to avoid it & $28.2 \%$ & $37.1 \%$ & $20.3 \%$ & $8.1 \%$ & $6.3 \%$ \\
\hline Turn to professional for help & $65.9 \%$ & $19.1 \%$ & $9.4 \%$ & $3.4 \%$ & $2.2 \%$ \\
\hline Look for information in internet to solve problem & $50.6 \%$ & $22.5 \%$ & $15.8 \%$ & $6.8 \%$ & $4.2 \%$ \\
\hline $\begin{array}{l}\text { Turn to internet for help: For example, to express } \\
\text { feelings in Facebook, Micro-Blog. }\end{array}$ & $44.3 \%$ & $25.4 \%$ & $15.2 \%$ & $8.5 \%$ & $6.6 \%$ \\
\hline
\end{tabular}


Table 5. The relationship among three kinds of negative emotions, difficulty-handling strategies, and cognitive emotion regulation strategies.

\begin{tabular}{lcccccc}
\hline & \multicolumn{2}{c}{$\begin{array}{l}\text { Junior middle school } \\
\text { (grade one and grade two) }\end{array}$} & \multicolumn{3}{c}{$\begin{array}{c}\text { Senior middle school } \\
\text { (grade three to grade six) }\end{array}$} \\
\hline & $\begin{array}{c}\text { Depressive } \\
\text { symptom }\end{array}$ & $\begin{array}{c}\text { Anxiety } \\
\text { symptom }\end{array}$ & $\begin{array}{c}\text { Stress } \\
\text { symptom }\end{array}$ & $\begin{array}{c}\text { Depressive } \\
\text { symptom }\end{array}$ & $\begin{array}{c}\text { Anxiety } \\
\text { symptom }\end{array}$ & $\begin{array}{c}\text { Stress } \\
\text { symptom }\end{array}$
\end{tabular}

\begin{tabular}{|c|c|c|c|c|c|c|}
\hline Daily problems & $4^{* * *}$ & $4^{* * *}$ & $4^{* * *}$ & $4^{* * *}$ & $4^{* * *}$ & $4^{* * *}$ \\
\hline \multicolumn{7}{|c|}{ Difficulty-handling strategies } \\
\hline \multicolumn{7}{|l|}{ Talking with others to release my anxiety } \\
\hline Talking with others to solve problems & & & & & & $\downarrow^{*}$ \\
\hline \multicolumn{7}{|l|}{ Find a way to release } \\
\hline Neglect problems & $4^{* * *}$ & $4^{*}$ & $4^{* *}$ & $4^{* * *}$ & $4^{* * *}$ & $4^{*}$ \\
\hline \multicolumn{7}{|l|}{$\begin{array}{l}\text { Looking for information in } \\
\text { internet to solve problems }\end{array}$} \\
\hline Turn to internet for emotion support & & & $4^{* *}$ & & & \\
\hline \multicolumn{7}{|c|}{ Cognitive emotion regulation strategies } \\
\hline Self-blaming & $4^{* * *}$ & $4^{* *}$ & $4^{* * *}$ & $4^{* * *}$ & $4^{* * *}$ & $4^{* *}$ \\
\hline Rumination & $4^{* *}$ & $\boldsymbol{4}^{* * *}$ & $4^{* * *}$ & $4^{* *}$ & $4^{* * *}$ & $4^{* * *}$ \\
\hline Other-blame & & $4^{*}$ & $4^{* *}$ & & & $4^{* *}$ \\
\hline Catastrophising & $4^{* * *}$ & $4^{* * *}$ & $4^{* * *}$ & $4^{* * *}$ & $4^{* * *}$ & $4^{* * *}$ \\
\hline Acceptance & $4^{*}$ & & & $4^{*}$ & & \\
\hline Positive refocusing & & & & & & $\downarrow^{* *}$ \\
\hline Refocusing on planning & $\downarrow^{*}$ & & & $\downarrow^{*}$ & & $4^{*}$ \\
\hline Positive reappraisal & $\downarrow^{* * *}$ & & $\downarrow^{* *}$ & $\downarrow^{* * *}$ & $\downarrow^{* * * *}$ & $\downarrow^{* *}$ \\
\hline Putting into perspective & & & & & & \\
\hline
\end{tabular}

Note: $\uparrow$ stands for positive influence, enforce this negative emotion; $\downarrow$ stands for negative influence, lessen this negative emotion. ${ }^{*} p<0.05 ;{ }^{* *} p<$ $0.01 ;{ }^{* * *} p<0.001$.

rious depression, anxiety, and stress they would have. When those students who used this strategy encountered difficulties, they would not try to solve problem, or talk with others. They were not willing to face the problem and their own emotion, just dreaming that the problem will disappear itself. This was an escape and self-deception. As a result, the problem may turn worse, and even lead to more and more serious negative emotion. (In the analysis of this part, the item "turn to professional for help" was not included, because the result of Hong Kong's research showed that this item may be the result but not the reason of negative emotion.

In these nine kinds of cognitive emotion regulation strategies, negative strategies had more influence than positive strategies. In the negative strategies, "self-blaming”, "rumination" and "catastrophising” were the main strategies that lead to negative emotion; this result was the same as the western research (e.g., [13] [16]). When the students encounter difficulties, if they tend to blame themselves for the negative things, or exaggerate the negative result of negative things, or imagine that this will be serious or hard to solve, their depression, anxiety and stress will be worse. It is well supported by substantial literature. "Rumination” means, when negative things happen, the students think about the thoughts and feelings associated with the negative event, but do not do anything to solve the problem. In this way, the problem would not be solved, while the negative emotion becomes worse and worse. "Other-blame" only influenced anxiety and stress of the students of grade one and grade two, and stress of students over grade three. "Other-blame” means that, when negative things happen, students tend to put the blame on others. Then, they will not try to solve problems, but feel much more worthless. 
This thought may release unhappy feeling temporarily, but if it is used too much, it may arouse feeling of helpless or uncontrolled. Added to unsolved event, anxiety and stress will emerge. "Other-blame" was not the factor of depressive emotion. The reason could be attributed to the negative self-concept of the people with depression [28], who tend to blame themselves rather than others.

In those five positive cognitive emotion regulation strategies, only "positive reappraisal" had significant influence. Students could decrease the level of depression, anxiety and stress when they apply the "positive reappraisal" strategy, such as recombination of ideas and ideas changes, positive evaluation on the negative events, and seeking the positive influence on individual development. For example, if someone's wallet is stolen, he/she could tell himself/herself that it is a lesson to learn to be more careful; or if one is impolite to him/her, he/she could tell himself/herself not to do the same, but to be polite and respectful.

In the results that were related to cognitive emotion regulation strategies, one point does not agree with the theory. According to the theory, "acceptance" can release the negative emotion aroused by unpleasant experience. "Acceptance" means people would accept the reality even if something happened and could not be changed. In this research, both the junior middle school students and senior middle school students, the students' depressive emotion would be exacerbated though they were adopting the "acceptance" strategy in the daily life, but this did not apply to students with anxiety and stress problems. Some researches in the west also got the similar results: "acceptance" had positive correlation with depressive emotion for the old [15] and college students [16]. Those people suffered from depression usually had a set of "negative thinking mode" [28]. They treated themselves, the world, and the future with a set of negative ideas. "Learned helpless" theory believed that there was a kind of "helpless" and "uncontrolled" belief behind this "negative thinking mode", and "acceptance" strategy may reflect this kind of belief. The reason that students used "Acceptance" strategy might be due to their "helplessness" where they might turn to desperation in the end. But this did not mean they felt at ease, on the contrary, depression emerged.

This research showed that "refocusing on planning" can release depression, but it would increase stress symptom of high grade students. "Refocusing on planning" means to plan actively and do something to deal with the problem on hand. This kind of thinking mode stands for active attitude, and against the negative attitude behind depression. As said above, those people influenced by depression had a kind of "helpless" feeling or idea. So adopting an active strategy, "refocusing on planning" can help people to avoid depressive emotion when they encounter difficulties or unpleasant events. However, when the students of high grade face difficulties related to study or the future, it is difficult to plan to change present situation and solve problem. We can imagine that "refocusing on planning" Could bring us stress.

In this research, "positive refocusing" had an inverse relationship between the high grade students and their stress levels. It referred to that the more students use this strategy, the less their stress will be. "Positive refocusing" means to focus on some pleasant issues, while not to think about that negative event. In other words, "Positive Refocusing" has a similar effect as "Escape", where people tend to put the problem away, not to think about it and focus on some pleasant issues, thus to release negative emotion. This is not very active thinking, but it can give people a respite. For those who are mature enough or students in senior grades, they will face the problem again after experiencing stress emotion. Otherwise, if people only use this strategy to deal with problem, while not use in other ways, their negative emotion will increase.

In this research, "putting into perspective" was the only thinking mode that had no influence on middle school students' negative emotion in Macau. "Putting into perspective" means thoughts of playing down the seriousness of the event or emphasizing its relativity when compared to other events. Theoretically, "putting into perspective" means there are many bad things in life, so the event on hand comparatively seems to be not so serious. But for the middle school students, they only have limited experience, and have not experienced some hard difficulties. So it is not so easy to ask them to treat the event on hand as a drop in the ocean.

As a whole, this research found that the negative thinking strategies had more influence than the positive thinking strategies, but this did not mean the positive thinking strategies had no influence. Compared with the negative thinking strategies, the positive thinking strategies demand high requirement of students' abstract thinking ability, hypothesis and reasoning ability, analysis and general ability. So the positive thinking strategies are difficult to use and needed to be learned. Hence, the adults not only need to help students get rid of the negative thinking strategies, but also need to train them to use the positive thinking strategies.

Moreover, the result also showed that cognitive emotion regulation strategies had more influence than the difficulty-handling strategies. That is to say, if we try to change the students' negative emotion, to change their idea 
is more important than to change their behavior. Besides, when people encounter difficulties, the idea usually pops up right before the action. If they have negative idea, they will have negative emotion, and then take negative difficulty-handling strategies.

\section{Suggestions and Conclusion}

Based on this research's data, the working group gives the following suggestions for the middle school students' mental health in Macau:

1. This research showed depression, anxiety and stress situation of middle school students in Macau. Although the data showed that most students' situation was normal, but a part of students' mental health are still not so ideal, and needed to pay attention to. Nobody can avoid different kinds of stress. The stress itself is not a disease, and it can also become a kind of motivation force on development. When the stress is too much to influence individual's development, study, and social adjustment, it will arouse serious emotion problem. So parents and teachers should improve their sensitivity to students' emotion, pay special attention to how they deal with stress on study, offer them better communication channels, and let the students have proper topics and chances to talk.

2. As World Health Organization (WHO) suggested that precaution is better than treatment, and the first step of precaution is education. WHO's suggestion about mental health literacy are fully supported by us. We propose to increase middle school students, parents, teachers and youth worker's knowledge on adolescent mental health through public education, such as lectures, brochures, etc. So that people's needs on mental health service could be better fulfilled and the chances of delayed treatment could also be reduced. It will also help the youth to get timely support actively and without any qualms.

3. We suggest launch a campaign at schools, like adding new classes about middle school students' mental health. The content should include positive philology, difficulty-handling method, and working under pressure, in order to help them build positive and healthy self-image and values. On the other hand, we should promote youth groups to pay more attention to their personal and peer's emotion and mental health through various activities, and provide adolescents with related information and knowledge.

4. As the middle school students' thinking mode is related to their emotion health, we suggest make the course of cognitive and emotional health universal in the middle school students, thus to help them built up healthy and positive thinking mode, and help to prevent and improve adolescent depression and anxiety directly. The research showed that students' thinking mode and emotion-dealing method were related to their emotional situation. In order to help students to build up healthy thinking mode, we suggest expand classes and groups based on cognitive behavior theory, and let students understand how their thinking modes influence their emotion. These kinds of classes and groups have been promoted in Australia and Canada, etc.

5. Except for nipping it in the bud, early awareness and intervention are very important. So we hope we can develop a set of valid evaluation tools for adolescent mental health, investigate adolescent mental and physical health regularly, and obtain information about the middle school students' mental and physical health. Every year, "mental health investigation on the middle school students" should be carried out. On one hand, the local data collection could help people to allocate resources based on the reality and to develop a proper service system. On the other hand, it can differentiate those adolescents with emotion troubles, the source of stress and their needs so as to provide them with proper support.

6. Through adolescent mental health support service, people can provide help as soon as possible to those adolescences with serious emotional symptom; provide professional evaluation and follow up services to avoid that difficulties disturbing students' daily life seriously. In this regard teachers and parents should be encouraged to enforce adolescent mental health knowledge, thus to discriminate those students who need personal support. In addition, through mental health education, schools can allege that they will treat emotional health problem with positive and acceptant attitude. In this way, schools can help students get help without any taboo and look for help actively.

\section{Conclusion}

It is important for adolescents to face challenges, family, social and personal development in a healthy, positive and active way. This plan hope to investigate adolescents' mental and physical health regularly in order to understand the real situation and relative factors; to allocate resources according to reality and develop a proper 
service system; to promote adolescences, parents, teachers and youth worker to pay more attention to adolescent mental health. Finally, thank all the schools which participated in this research for your help and assistance so the research can be such successful.

\section{References}

[1] Chan, S.M. (2012) Early Adolescent Depressive Mood: Direct and Indirect Effects of Attributional Styles and Coping. Child Psychiatry and Human Development, 43, 455-470. http://dx.doi.org/10.1007/s10578-011-0275-9

[2] Chan, S.M., Chan, S.K. and Kwok, W.W. (in Press) Ruminative and Catastrophizing Cognitive Styles Mediated the Association between Daily Hassles and High Anxiety in Hong Kong Adolescents. Child Psychiatry and Human Development.

[3] Essau, C.A., Leung, P.W.L., Conradt, J., Cheng, H. and Wong, T. (2008) Anxiety Symptoms in Chinese and German Adolescents: Their Relationship with Early Learning Experiences, Perfectionism, and Learning Motivation. Depression and Anxiety, 25, 801-810. http://dx.doi.org/10.1002/da.20334

[4] Shah, F. and Morgan, S.B. (1996) Teacher's Ratings of Social Competence of Children with High versus Low Levels of Depressive Symptoms. Journal of School Psychology, 34, 337-349. http://dx.doi.org/10.1016/S0022-4405(96)00019-2

[5] Van Ameringen, M. and Farvolden (2003).

[6] Mallett, C.A., Dare, P.S. and Seck, M.M. (2009) Predicting Juvenile Delinquency: The Nexus of Childhood Maltreatment, Depression and Bipolar Disorder. Criminal Behaviors and Mental Health, 19, 235-246. http://dx.doi.org/10.1002/cbm.737

[7] Politano, P.M., Edinger, D.L. and Nelson, W.M. (1989) Comparisons of Conduct and Affective Disordered Youth: A Psychometric Investigation of Responses to the Children's Depression Inventory. Journal of Child Psychology and Psychiatry, 30, 431-438. http://dx.doi.org/10.1111/j.1469-7610.1989.tb00256.x

[8] Aronen, E.T. and Soininen, M. (2000) Childhood Depressive Symptoms Predict Psychiatric Problems in Young Adults. Canadian Journal of Psychiatry, 45, 465-470.

[9] Chen, X., Hastings, P.D., Rubin, K.H., Chen, H., Cen, G. and Stewart, S.L. (1998) Child-Rearing Attitudes and Behavioral Inhibition in Chinese and Canadian Toddlers: A Cross-Cultural Study. Developmental Psychology, 34, 677-686. http://dx.doi.org/10.1037/0012-1649.34.4.677

[10] Cheng, S.-T. and Li, K.-K. (2010) Combining Major Life Events and Recurrent Hassles in the Assessment of Stress in Chinese Adolescents: Preliminary Evidence. Psychological Assessment, 22, 532-538. http://dx.doi.org/10.1037/a0019579

[11] Stefane, Strohmeie, Fandre and Spiel (2012).

[12] Lazarus, R. and Folkman, S. (1984) Stress, Appraisal and Coping. Springer, New York.

[13] Garnefski, N., Kraaij, V. and Spinhoven, P. (2001) Negative Life Events, Cognitive Emotion Regulation and Emotional Problems. Personality and Individual Differences, 30, 1311-1327. http://dx.doi.org/10.1016/S0191-8869(00)00113-6

[14] Garnefski, N., Legerstee, J.S., Kraaij, V., van den Kommer, T. and Teerds, J. (2002) Cognitive Coping Strategies and Symptoms of Depression and Anxiety: A Comparison between Adolescents and Adults. Journal of Adolescence, 25, 603-611. http://dx.doi.org/10.1006/jado.2002.0507

[15] Garnefski, N. and Kraaij, V. (2006) Relations between Cognitive Emotion Regulation Strategies and Depressive Symptoms: A Comparative Study of Five Specific Samples. Personality and Individual Differences, 40, 1959-1669. http://dx.doi.org/10.1016/j.paid.2005.12.009

[16] Martin, R.C. and Dahlen, E.R. (2005) Cognitive Emotion Regulation in the Prediction of Depression, Anxiety, Stress and Anger. Personality and Individual Differences, 39, 1246-1260. http://dx.doi.org/10.1016/j.paid.2005.06.004

[17] Tolan, Gorman-Smith, Henry, Chung and Hunt (2002).

[18] Murberg, T.A. and Bru, E. (2005) The Role of Coping Styles as Predictors of Depressive Symptoms among Adolescents: A Prospective Study. Scandinavian Journal of Psychology, 46, 385-393. http://dx.doi.org/10.1111/j.1467-9450.2005.00469.x

[19] DASS-21.

[20] Lovibond, S.H. and Lovibond, P.F. (1995) Manual for the Depression Anxiety Stress Scales. Psychology Foundation, Sydney.

[21] Wong, Cheung, Chan, Ma and Tang (2006).

[22] Wong and Mak (2013).

[23] Essau, C.A., Conradt, J. and Petermann, F. (2000) Frequency, Comorbidity, and Psychosocial Impairment of Anxiety 
Disorders in German Adolescents. Journal of Anxiety Disorders, 14, 263-279. http://dx.doi.org/10.1016/S0887-6185(99)00039-0

[24] Essau, C.A., Muris, P. and Ederer, E.M. (2002) Reliability and Validity of the Spence Children's Anxiety Scale and the Screen for Child Anxiety Related Emotional Disorders in German Children. Journal of Behavior Therapy and Experimental Psychiatry, 33, 1-18. http://dx.doi.org/10.1016/S0005-7916(02)00005-8

[25] Rudolph, K.D. (2002) Gender Differences in Emotional Responses to Interpersonal Stress during Adolescence. Journal of Adolescent Health, 30, 3-13. http://dx.doi.org/10.1016/S1054-139X(01)00383-4

[26] Shek (1991).

[27] Lee, S., Tsang, A., Chui, H., Kwok, K. and Cheung, E. (2007) A Community Epidemiological Survey of Generalized Anxiety Disorder in Hong Kong. Community Mental Health Journal, 43, 305-319. http://dx.doi.org/10.1007/s10597-006-9077-0

[28] Beck, A.T. (1967) Depression. Harper \& Row, New York. 